\section{Outlook following "somnolence syndrome" after prophylactic cranial irradiation}

The "somnolence syndrome" consists of drowsiness, lethargy, anorexia, and irritability occuring in about $60 \%$ of children six weeks after prophylactic irradiation of the central nervous system in acute leukaemia or non-Hodgkin's lymphoma. ${ }^{1}$ It is associated with electroencephalographic (EEG) abnormalities. ${ }^{12}$ We have studied 27 children prospectively to evaluate EEG changes occurring in children after irradiation of the central nervous system. We have also attempted to correlate the occurrence of the syndrome with the fractionation of radiotherapy and with the subsequent survival and well-being of the children.

\section{Patients, methods, and results}

The study group consisted of 17 children with acute lymphoblastic leukaemia and 10 children with non-Hodgkin's lymphoma; there were 18 boys and nine girls and their median age was $5 \cdot 2$ years. Twenty-four children received 2400 rads of cranial irradiation with five doses of $10 \mathrm{mg} / \mathrm{m}^{2}$ (maximum $12 \mathrm{mg}$ ) methotrexate intrathecally. Three children also received spinal irradiation with 1000 rads and no intrathecal methotrexate.

Seventeen of the 27 children $(63 \%)$ had clinically significant somnolence after cranial irradiation. The syndrome occurred irrespective of type of disease, sex, or age of the patient. EEG abnormalities occurred in nine out of ten children who had EEG examination during somnolence (see figure) and

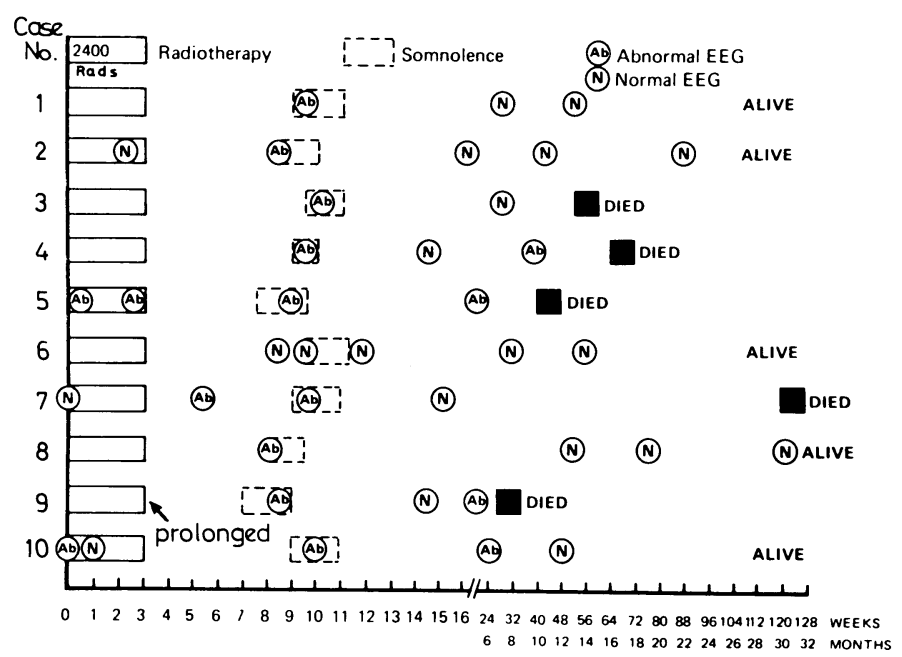

Electroencephalographic results of nine patients who had an EEG taken during the somnolence syndrome.

subsequently returned to normal in eight of these children. The abnormalities consisted of pathological symmetrical slowing of the dominant rhythm or increase to excess of the diffuse theta and slow components, given the level of awareness of the children. The one child whose EEG failed to return to normal died with systemic relapse of lymphoma 11 months after diagnosis.

Children receiving their radiotherapy in fewer than 16 fractions and less than 22 days had a higher incidence of somnolence (12 out of 16 children) than those receiving more than 19 fractions in more than 24 days (four out of 10 children somnolent). Although this disparity could be due to chance variation, the difference may be due to the greater biological effect of radiation when given in fewer fractions.

There was no significant difference between the survival of children who developed somnolence (median survival 36 months) and that of nonsomnolent children (median survival 27 months), nor was there an increase in central nervous system relapse in somnolent children. Somnolence was unrelated to taking adriamycin or colaspase as part of the systemic chemotherapy.

\section{Comment}

The benign nature of the somnolence syndrome is confirmed in this study. Knowledge of its existence is important for reassuring children and their parents and for preventing unnecessary investigation.

We are very grateful to Mrs Sharon Willmott for co-ordinating this study and to Mrs Jane Thomas and Mrs Jill Nichol for carrying out the electroencephalography. We are indebted to our colleagues who kindly referred these children to us.

${ }^{1}$ Freeman, J E, Johnston, P G B, and Voke, J M, British Medical fournal, $1973,4,523$.

${ }^{2}$ Garwicz, S, et al, Acta Paediatria Scandinavica, 1975, 64, 339.

(Accepted 11 November 1977)

Imperial Cancer Research Fund, Department of Medical Oncology, St Bartholomew's Hospital, London EC1A 7BE

D PARKER, DPHIL, MRCP, Hamilton Fairley fellow

J S MALPAS, DPHIL, FRCP, consultant physician and director of unit

R SANDLAND, FRCS, FRCR, consultant radiotherapist

P C SHEAFF, MRCP, consultant clinical neurophysiologist

J E FREEMAN, MRCP, FRCR, consultant radiotherapist (present address chief of staff, Cancer Therapy and Research Centre, Cancer Therapy and

Research Foundation of South Texas, San Antonio, Texas, 78229 USA) A PAXTON, MRCPATH, consultant haematologist

\section{Blood pressure and kilopascals}

The use of kilopascals for measuring blood pressure was recommended in 1960 by the General Conference on Weights and Measures in its authorisation of the SI system, ${ }^{1}$ but it has not so far been accepted by the medical profession. I have been using kilopascals since 1976 and have found the changeover quite simple.

\section{Conversion from $\mathrm{mm} \mathrm{Hg}$ to $\mathrm{kPa}$}

I recalibrated the near side of the $2 \mathrm{~mm}$ scale on my wall mercury sphygmomanometer in kilopascals (integers only) and started to use this exclusively. For the first three months the opposite $2 \mathrm{~mm}$ scale was left to make conversion easier. Then I recalibrated this as well and converted to $\mathrm{mm} \mathrm{Hg}$ only when essential; all blood pressure readings for FP7 and 8 forms, insurance reports, maternity co-operation cards, and hospital correspondence are now given in kilopascals, the $\mathrm{mm} \mathrm{Hg}$ equivalents being added in parentheses where necessary.

A pressure of 1 kilopascal $(\mathrm{kPa})$-the force exerted by 1 newton on an area of $1 \mathrm{~m}^{2}$-is equal to $7.5 \mathrm{~mm} \mathrm{Hg}$ (see table). Thus $1 \mathrm{kPa}$ is represented by $3 \frac{1}{2}$ intervals on the usual $2 \mathrm{~mm}$ sphygmomanometer scale.

kPa-mm $\mathrm{Hg}$ conversion for blood pressure readings

\begin{tabular}{cc|cc}
\hline $\mathrm{kPa}$ & $\mathrm{mm} \mathrm{Hg}$ & $\mathrm{kPa}$ & $\mathrm{mm} \mathrm{Hg}$ \\
\hline 8 & 60 & 24 & 180 \\
10 & 75 & 28 & 210 \\
12 & 90 & 32 & 240 \\
16 & 120 & 36 & 270 \\
20 & 150 & 40 & 300
\end{tabular}

I record the pressure to the nearest integer and do not regard the larger units as a disadvantage. With so many variables influencing recordings, the precise detail of millimetre measurement is both unnecessary and unrealistic. (Observer variation of about $2 \mathrm{kPa}$ in the pulse pressure recorded may be contributed just by the phase of respiratory excursion-inspiration may raise the systolic reading by about $1 \mathrm{kPa}$ and expiration may lower the diastolic reading by the same amount.) Physicians do not in fact record the pressure precisely in millimetres-I always recorded readings to the nearest $5 \mathrm{~mm}$, and nurses tend to record them to the nearest $10 \mathrm{~mm}$. Even for critical readings (for example, for insurance examinations and in serious obstetric conditions) I measure to the nearest $\mathrm{kPa}$ but take three readings, with a pause-not, however, 5 minutes as commonly recommended-and a deep breath between each one. Readings of $0.5 \mathrm{kPa}$ could if desired be used for precise measurements needed by scientific work.

Hart's criteria ${ }^{2}$ for the management of asymptomatic hypertension must now be translated into kilopascals. Hart regards $100,105,110$, and 115 $\mathrm{mm} \mathrm{Hg}$ as the critical diastolic levels in different circumstances-in $\mathrm{kPa}$ $13.3,14,14 \cdot 7$, and $15 \cdot 3$, which is clearly unsatisfactory. Since using kilopascals I have come to regard the danger level as between 12 and $16 \mathrm{kPa}$ 
(90-120 $\mathrm{mm} \mathrm{Hg}$ ), being individual to the patient (but it should be reassessed every 1-3 months). The narrower equivalent range of $13-15 \mathrm{kPa}$ -with a critical arithmetic mean of $14 \mathrm{kPa}(105 \mathrm{~mm} \mathrm{Hg})$-could, however, be used; only extensive statistical evaluation will determine the most clinically realistic range.

\section{Comment}

Nurses and midwives have shown interest in the use of kilopascals; in our practice the nurses have asked for their wall sphygmomanometer in the treatment room to be recalibrated. Insurance societies in my experience have accepted kilopascals in insurance reports. Consultants are amused and say that they always check blood pressure in their own way; but clinicians could give a lead here-and in any case teaching hospitals are starting to teach students kilopascals and their eventual adoption is intended officially.

${ }^{1}$ Baron, D N, British Medical fournal, 1974, 1, 509.

2 Hart, J Tudor, fournal of the Royal College of General Practitioners, 1975, 25, 160.

(Accepted 13 October 1977)

Blackwater, Hants

JOHN PRICE, MRCOG, MRCGP, general practitioner

\section{Drug supply requirements for patients discharged from hospital}

A proportion of patients leaving hospital receive a quantity of drugs to ensure continuity of treatment. It is generally agreed that the amount of drugs supplied should be small, since changes may be necessary under general practice conditions. ${ }^{1}$ Most studies of this nature have concentrated on drug compliance, but none has measured the time interval between discharge and initial contact with the general practitioner. Our prospective study was designed to measure this factor, since many hospitals arbitrarily dispense a 10-day supply of drugs.

\section{Patients, methods, and results}

The study was based in Pilgrim Hospital, a new district general hospital in South Lincs; beforehand the co-operation of all general practitioners, hospital consultants, and nursing staffs was sought. Over two months (February -March 1977) the hospital pharmacy kept a prospective log of all medicines dispensed for discharged patients. A simple form was issued with all such medicines, tabulating the necessary information, which was included in the initial discharge letter to the patient's general practitioner. The general practitioner was asked to return the form on the first contact by the patient after discharge indicating the date and whether the patient already had a supply of similar medicines. After two months the general practitioners of all patients whose forms had not been returned were approached and asked for details of patient contact.

Patients discharged to other hospitals or convalescent homes were excluded from the study. In the period of the study 613 of the $2086(29.4 \%)$ patients took drugs home. The general practitioners of 18 patients could not be identified. Of a possible 595 forms, $455(76.5 \%)$ were returned. Three patients died after discharge and 44 data forms were incomplete. Data on the remaining $408(67 \%)$ patients are shown in the figure. A total of 281 (69\%) patients contacted their general practitioner within the seven days of discharge, and $294(72 \%)$ by 10 days. At one month $83(20 \%)$ had made no contact with their general practitioner. 1239 discharge medicines were dispensed, the commonest agents being cardiovascular (242), antibiotics (194), central nervous system (188), mineral and vitamin supplements (157), hormonal preparations (106), and analgesics (85) - these together comprising $78 \%$ of all discharge medicines. $148(24 \%)$ patients took home three or more medicines. Statistical analysis showed no correlation among sex, age, number

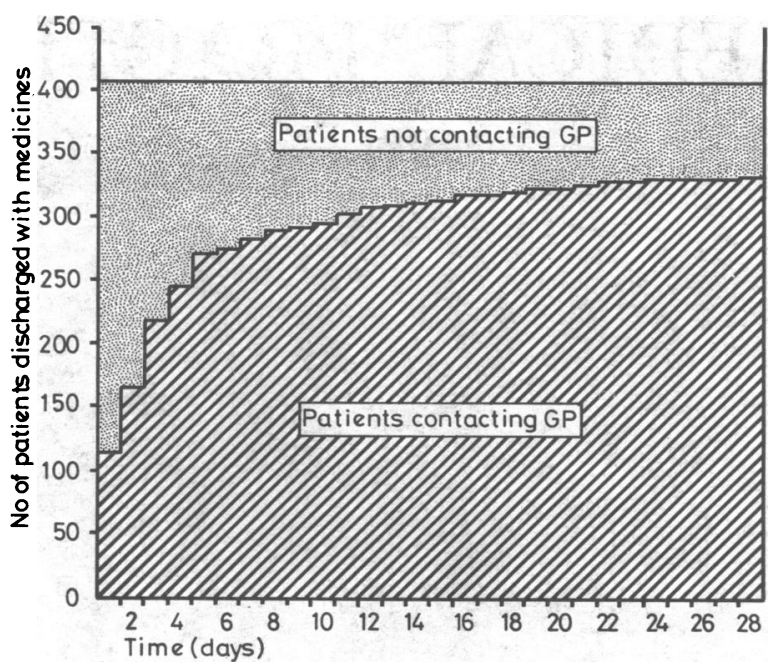

Numbers of patients who contacted their GPs after discharge.

or types of medicines prescribed, or initial contact time. Nevertheless, of the 132 patients who already had similar medicines, $118(89 \%)$ made contact with their general practitioner within seven days, and only nine $(7 \%)$ had made no contact by 28 days. A random sample of 144 patients discharged home during this period without medicines showed that $102(71 \%)$ had contacted their general practitioner within 10 days, and $18(12.5 \%)$ had made no contact by one month.

\section{Comment}

The results show that initial contact time is unaffected by the number or types of discharge medicines. Similar proportions of patients with and without discharge medicines had contacted their general practitioner within 10 days, suggesting that patient-doctor contact within 10 days of leaving hospital might be independent of the prescribing of medicines. Some $89 \%$ of patients who already had similar medicines at home made contact within 10 days of leaving hospital, suggesting that chronic illness is an important factor influencing earlier doctor contact.

A 10-day supply of medicines would seem to be adequate for most patients' needs on leaving hospital. Our figures indicate it may be feasible to reduce discharge drugs to a seven-day supply, although a further study of relative costing of hospital/general practice dispensing would be necessary before implementation.

We should like to thank all the hospital staffs and general practitioners who helped in this study.

1 Wilson, G M, Prescribers' fournal, 1972, 12, 63.

(Accepted 23 November 1977)

Pilgrim Hospital, Boston, Lincs

$S$ P DEACON, MB, CHB, general practice vocational trainee

L HAMMOND, MPS, pharmacist

B THOMPSON, MPS, district pharmaceutical officer

\section{Correction}

\section{Cardic arrhythmias in thalassaemia major}

In the paper by Drs S B Kaye and Marie Owen (11 February, p 342), under Patients, methods, and results the last sentence should read: "Five of six inadequately chelated patients . . . ( $<<0.001)$." The following should be added to the legend of the figure: "Individual patients are numbered." 